\title{
ESTUDO DA OBTENÇÃO DE FRAÇÕES RICAS EM HIDROCARBONETOS A PARTIR DE ÓLEO DE PALMA ATRAVÉS DA DESTILAÇÃO FRACIONADA EM DIFERENTES ESCALAS
}

\author{
O. A. CORRÊA ${ }^{1}$, H. S. ALMEIDA ${ }^{2}$, J. G. EID ${ }^{1}$, C. C. FERREIRA ${ }^{1}$, R. M. LOURENÇO ${ }^{1}$, S. A. P. \\ MOTA $^{3}$, N. T. MACHADO ${ }^{4}$ \\ ${ }^{1}$ Universidade Federal do Pará, Programa de Pós-Graduação em Engenharia Química \\ ${ }^{2}$ Universidade Federal do Pará, Faculdade de Engenharia Ambiental e Sanitária \\ ${ }^{3}$ Universidade Federal do Sul e Sudeste do Pará, Faculdade de Engenharia de Materiais \\ ${ }^{4}$ Universidade Federal do Pará, Faculdade de Engenharia Química \\ E-mail para contato: acneto08@gmail.com
}

\begin{abstract}
RESUMO - O principal objetivo deste trabalho foi analisar o potencial da destilação fracionada (DF) na obtenção de frações ricas em hidrocarbonetos semelhantes aos derivados do petróleo. Vale ressaltar que foram usadas diferentes colunas e escalas de destilação, entretanto o produto a ser destilado denominado Produto Líquido Orgânico (PLO), foi o mesmo. O PLO destilado foi obtido através do craqueamento térmico catalítico do óleo de palma e este apresentou um índice de acidez equivalente a $82,4 \mathrm{mg} \mathrm{KOH} / \mathrm{g}$. O processo de destilação foi realizado em uma Unidade Piloto de Destilação e em uma Unidade de Destilação em Escala de bancada e as colunas usadas foram: coluna do tipo empacotamento constituída por prateleiras de vidro fundido e preenchida com anéis de raschig (Destilação Piloto) e uma coluna do tipo Vigreux sem empacotamento e constituída de três estágios (Destilação Bancada). Após o processo de destilação verificou-se que ambos os processos obtiveram excelente rendimento para a biogasolina.
\end{abstract}

\section{INTRODUÇÃO}

A constante preocupação relacionada a um possível esgotamento das principais fontes de energia como o petróleo, carvão e gás natural e a conscientização mundial no que condiz a questão socioambiental evidencia a necessidade de mudanças nos hábitos de consumo das populações altamente dependentes do petróleo e a busca por combustíveis derivados de fontes renováveis (MOTA, 2013). Desta forma a biomassa sólida e/ou líquida está emergindo como uma promissora matéria prima para a obtenção de biocombustíveis (DEMIRBAS, 2007). Nesse contexto é corroborada a busca e incentivo a pesquisas e desenvolvimento de novos combustíveis obtidos de 
fontes renováveis, os chamados biocombustíveis (SANTOS et al., 2009).

O processo de craqueamento ou pirólise é um dos mais importantes processos na indústria de refinaria de petróleo, o qual também é aplicado na produção de biocombustíveis obtidos a partir de biomassas (WANG et al., 2008). O processo de craqueamento de óleos e gorduras é basicamente realizado com o objetivo de produzir biocombustíveis ricos em frações de substâncias similares à gasolina, querosene e diesel de origem fóssil (BARROS et al., 2008). Apesar da simplicidade operacional do processo de craqueamento, ao utilizar apenas a elevação de temperatura, o produto obtido (PLO) apresenta uma grande desvantagem, pois a uma elevada formação de compostos oxigenados, os quais tornam o produto líquido orgânico altamente ácido, com isso susceptível a reações secundárias de degradação e corrosão (MOTA, 2013). Fato este que corroboraria a diminuição do tempo de vida útil do combustível, assim como a do motor no qual o mesmo fora acondicionado (WANG et al., 2008).

Com o objetivo de solucionar a questão da elevada concentração de compostos oxigenados, a seletividade do produto requerido, assim como atender as especificações exigidas pelos órgãos governamentais regulamentadores das normas para combustíveis de veículos automotivos, diversos estudos vem sendo desenvolvidos com foco na síntese de catalisadores (SANTOS, 2007) e aplicação de operações unitárias e ou processos de separação como a destilação, objetivando-se desta forma; realizar a desoxigenação, a diminuição do tempo reacional durante o processo de craqueamento, a diminuição da temperatura operacional de craqueamento, a seletividade do combustível requerido e a obtenção de um combustíveis dentro das especificações estabelecidas neste caso, pela Agência Nacional de Petróleo, Gás Natural e Biocombustíveis (ANP) (MOTA et al., 2010).

Segundo Treybal (1968), destilação é um método para separar componentes de uma solução, e a mesma depende da distribuição das substâncias entre uma fase de gás e um líquido, e aplica-se a casos em que todos os componentes se encontram presentes em ambas as fases, ele também ratifica que além da temperatura, a pressão é outro fator importante no processo de destilação. O ponto de ebulição de um determinado líquido é função da pressão a que ele está sendo submetido. Quanto maior for à pressão exercida, maior será a temperatura de ebulição do líquido. Assim, a diminuição da pressão acarreta na diminuição da temperatura de ebulição do líquido. A conjugação desses dois parâmetros (temperatura e pressão) permite que um líquido seja separado em diversas frações.

As aplicações da destilação têm a mais ampla diversidade. O petróleo, por exemplo, é separado inicialmente em diversas frações (como os gases leves, a nafta, a gasolina, o querosene, os óleos combustíveis, os óleos lubrificantes e o asfalto) em grandes colunas de destilação. Estas frações são processadas posteriormente em produtos acabados e a destilação é frequentemente utilizada nas etapas intermediárias da obtenção destes produtos finais (SANTOS, 2011).

Segundo Geankoplis (2008), a destilação pode ser realizada na prática por dois métodos principais. O primeiro método consiste em produzir um vapor aquecendo a mistura líquida a ser 


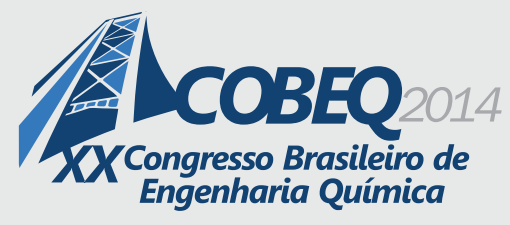

19 a 22 de outubro de 2014
Florianópolis/SC

separada num passo único. O segundo método envolve o refluxo do vapor não condensado. Este segundo método é chamado destilação fracionada, destilação de refluxo ou retificação.

Segundo Perry (2008), a destilação fracionada é um método de separação de líquidos presentes em misturas homogêneas e consiste em elevar a temperatura até o ponto de ebulição do líquido que apresente valor mais baixo para essa propriedade. Os componentes com baixo ponto de ebulição, os mais voláteis, conseguem contornar os obstáculos da torre e chegar ao topo da coluna, com isso, podem ser separados. Espécies químicas com pontos de ebulição mais altos (menos voláteis) não conseguem chegar ao topo, acumulando-se nos diversos níveis da torre da destilação, até que a temperatura do sistema alcance a temperatura de ebulição dessas substâncias, de forma que, assim, elas possam ser separadas, cada uma, na sua respectiva temperatura de ebulição. Quanto mais próximos forem os pontos de ebulição dos líquidos, menor o grau de pureza das frações destiladas.

Diante deste contexto, o principal escopo deste trabalho foi obter e analisar as frações ricas em hidrocarbonetos através da utilização da destilação fracionada em diferentes escalas. Vale ressaltar que foi usado a mesma matéria-prima (PLO produzido a partir do craqueamento térmico catalítico do óleo de palma), tanto na destilação piloto quanto na destilação de bancada. Após a obtenção das frações as mesmas foram acondicionas e levadas para serem analisadas no Laboratório de Biocombustíveis e Processos de Separações Térmicas (THERMTEK), pertencente à Faculdade de Engenharia Química da Universidade Federal do Pará. Foi comprovado que ambos os processos (destilação piloto e destilação em escala de bancada) apresentaram rendimentos próximos para biogasolina.

\section{MATERIAIS E MÉTODOS}

O produto líquido orgânico produzido através do craqueamento térmico catalítico do óleo de palma foi utilizado como matéria-prima nos processos de destilação fracionada em escala de bancada e destilação fracionada em escala piloto, o mesmo apresentou uma acidez equivalente a $30,45 \mathrm{mg}$ $\mathrm{KOH} / \mathrm{g}$. Vale ressaltar que foram introduzidos 10 litros e $400 \mathrm{ml}$ de PLO na coluna piloto e de bancada, respectivamente. O primeiro processo realizado foi a destilação fracionada em escala de bancada.

O aparato utilizado no primeiro processo é composto por um balão de fundo redondo para acondicionamento do PLO, o qual é constituído de borosilicato com capacidade de 1L; é composto por uma manta térmica (marca Quimis, modelo Q321A25, número 515 e potência de 315W), utilizada no aquecimento do PLO contido no balão volumétrico; por uma coluna de destilação do tipo Vigreux sem empacotamento e constituída de três estágios e acoplada a uma conexão (junta de 24/40) constituída de vidro borosilicato com finalidade de interligar a coluna vigreux com uma das extremidades do sistema de condensação; o qual era constituído por um condensador de casco e tubo feito de borosilicato, com um comprimento de $70 \mathrm{~cm}$. 
O sistema de coleta do destilado inicialmente era composto por um balão de fundo redondo, constituído de borosilicato e capacidade de $500 \mathrm{~mL}$, após um determinado período de tempo, o balão foi substituído por um funil de decantação constituído de borosilicato e capacidade de $500 \mathrm{~mL}$, devido a flexibilidade de coleta de material condensado. A Figura 1 mostra a Unidade de Destilação em Escala de Bancada usada na pesquisa.

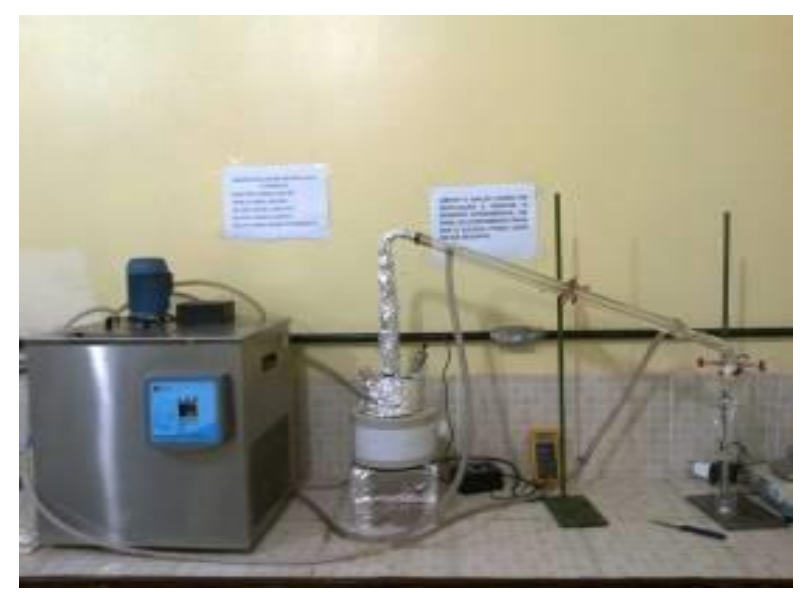

Figura 1 - Unidade de Destilação em Escala de Bancada (THERMTEK/FEQ/UFPA).

Após a realização de experimentos na unidade de destilação em escala de bancada, e consecutivamente análise dos dados produzidos, a pesquisa desenvolvida no presente trabalho foi direcionada para a próxima etapa, a qual consistiu na realização de experimentos na Unidade de Destilação Piloto, instalada no Laboratório de Biocombustíveis e Processos de Separações Térmicas (THERMTEK), pertencente à Faculdade de Engenharia Química da Universidade Federal do Pará.

A Unidade Piloto de Destilação, a qual pode ser operada com ou sem vácuo, é composta por, três (03) balões de fundo redondo, constituídos de borosilicato, com capacidades de 5L, 10L e 50L, sendo os dois primeiros utilizados como vasos de coleta de destilado e o terceiro como vaso de alimentação do material a ser destilado, além disso, estes apresentam na extremidade inferior uma válvula de descarga para a retirada do produto obtido da destilação e para a remoção do material residual, o qual fica depositado no fundo do balão de alimentação após o término do procedimento operacional.

A coluna de destilação piloto é constituída também por um banho aquecedor do tipo flameproof, com capacidade de 50L, o qual possui um sistema de aquecimento elétrico e um sistema de aquecimento a vapor, o banho de aquecimento é envolvido por um material isolante constituido de lã de rocha, o qual é envolvido por um revestimento de alumínio objetivando-se diminuir ao máximo 
as perdas de energia geradas pelo equipamento. A coluna piloto de destilação ainda possui uma extrutura cilindríca, contituida de borosilicato, a qual possui internamente pratileiras de vidro fundido, com a função de acondicionar o sistema de empacotamento, constituido de anés de raschig com 15 mm de comprimento cada um. A Figura 2, mostra a Unidade Piloto de Desttilação, instalada no Laboratório de Biocombustíveis e Processos de Separações Térmicas (THERMTEK), pertencente à Faculdade de Engenharia Química da Universidade Federal do Pará.

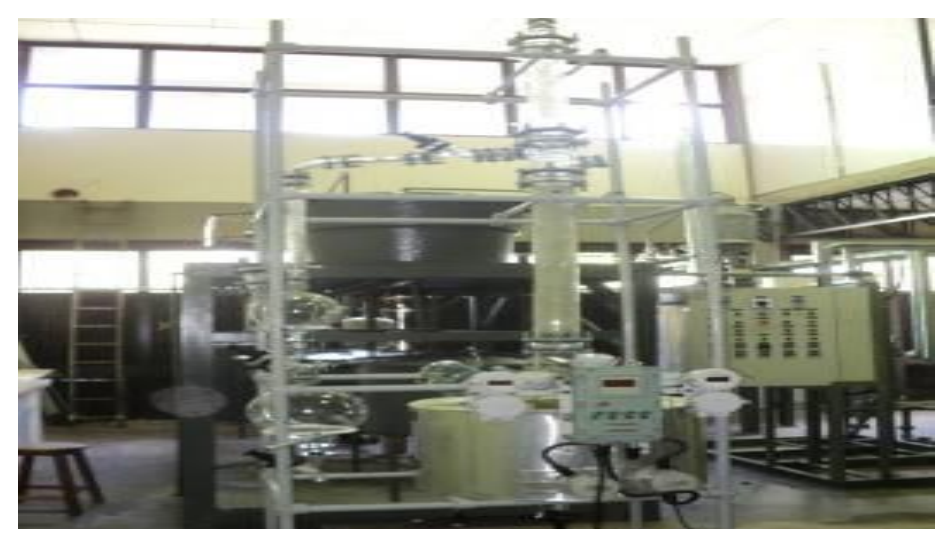

Figura 2 - Unidade de Destilação Piloto (THERMTEK/FEQ/UFPA).

Inicialmente visando obter hidrocarbonetos na faixa da gasolina derivada do petróleo, os sistemas de destilação foram programados para operar a uma temperatura máxima de $150{ }^{\circ} \mathrm{C}$, mantendo-se constante ao atingir esta temperatura, o aquecimento foi realizado a uma taxa de 5 ${ }^{\circ} \mathrm{C} / \mathrm{min}$. Após encerrar a condensação do produto obtido na respectiva faixa, o mesmo foi coletado.

Depois de coletar a primeira faixa de biocombustível, o controle de temperatura da coluna de destilação foi ajustado para operar até a uma temperatura máxima de $235^{\circ} \mathrm{C}$ com o objetivo de se obter hidrocarbonetos na faixa do querosene derivado do petróleo e logo em seguida objetivando-se separar frações de hidrocarbonetos na faixa do diesel derivado do petróleo, ajustou-se novamente o controle de temperatura das unidades de destilação, para operar a uma temperatura máxima de $305^{\circ} \mathrm{C}$, porém os processos de destilação só apresentaram um bom rendimento para biogasolina.

Por último, as amostras obtidas após o término dos processos de destilação foram submetidas a análises físico-químicas, como densidade, viscosidade, índice de acidez, índice de saponificação, índice de refração, corrosividade à lâmina de cobre, ponto de fulgor segundo os métodos estabelecidos pela Agência Nacional de Petróleo, Gás Natural e Biocombustíveis (ANP), American Society for Testing and Materials (ASTM); assim como, a American Oil Chemists Society (AOCS). 


\section{RESULTADOS E DISCUSSÃO}

A Tabela 1 apresenta os resultados da caracterização físico-química da biogasolina produzida através do processo de destilação fracionada em escala de bancada do produto líquido orgânico, entretanto os dados obtidos foram devidamente comparados com os valores estabelecidos pela resolução da ANP No 57 para gasolina do petróleo.

Tabela 1 - Resultados das análises físico-químicas da biogasolina produzida através da destilação fracionada em escala de bancada.

\begin{tabular}{|c|c|c|}
\hline Análises & Biogasolina (destilação bancada) & ANP No 57 \\
\hline Densidade $\left(\mathrm{g} / \mathrm{cm}^{3}\right)$ & 0,89 & $0,82-0,88$ \\
\hline Índice de acidez $(\mathrm{mg} \mathrm{KOH} / \mathrm{g})$ & 15,9 & - \\
\hline Índice de refração & 1,45 & - \\
\hline Ponto de fulgor $\left({ }^{\circ} \mathrm{C}\right)$ & 30 & $\geq 38$ \\
\hline Viscosidade cinemática $(\mathrm{cSt})$ & 5,6 & $2,0-4,5$ \\
\hline Índice de saponificação $(\mathrm{mg} \mathrm{KOH} / \mathrm{g})$ & 24 & - \\
\hline Corrosividade $(1 \mathrm{~A})$ & 1 & 1 \\
\hline
\end{tabular}

A Tabela 2 apresenta os resultados da caracterização físico-química da biogasolina produzida através do processo de destilação fracionada em escala de piloto do produto líquido orgânico, entretanto os dados obtidos foram devidamente comparados com os valores estabelecidos pela resolução da ANP No 57 para gasolina do petróleo.

Tabela 2 - Resultados das análises físico-químicas da biogasolina produzida através da destilação fracionada em escala piloto.

\begin{tabular}{|c|c|c|}
\hline Análises & Biogasolina (destilação piloto) & ANP N 57 \\
\hline Densidade $\left(\mathrm{g} / \mathrm{cm}^{3}\right)$ & 0,90 & $0,82-0,85$ \\
\hline Índice de acidez $(\mathrm{mg} \mathrm{KOH} / \mathrm{g})$ & 16,5 & - \\
\hline Índice de refração & 1,43 & - \\
\hline Ponto de fulgor $\left({ }^{\circ} \mathrm{C}\right)$ & 34 & $\geq 38$ \\
\hline Viscosidade cinemática $(\mathrm{cSt})$ & 9,4 & $2,0-4,5$ \\
\hline Índice de saponificação $(\mathrm{mg} \mathrm{KOH} / \mathrm{g})$ & 20,2 & - \\
\hline Corrosividade $(1 \mathrm{~A})$ & 1 & 1 \\
\hline
\end{tabular}




\section{9 a 22 de outubro de 2014 \\ Florianópolis/SC}

Ao analisar os resultados apresentados nas tabelas 1 e 2, podemos verificar que apesar dos valores obtidos através da destilação piloto e de bancada não apresentarem grande consonância com as especificações da sua respectiva norma (ANP $\mathrm{N}^{\mathrm{o}}$ 57), os mesmos apresentam dados bastantes aproximados e como exemplo temos os valores do índice de acidez, pois enquanto a biogasolina obtida através da destilação piloto apresentou uma acidez equivalente a $16,5 \mathrm{mg} \mathrm{KOH} / \mathrm{g}$ o mesmo biocombustível obtido através da destilação em escala de bancada apresentou uma acidez aproximada, correspondendo a $15,9 \mathrm{mg} \mathrm{KOH} / \mathrm{g}$.

Desta forma, podemos ratificar que a variação de escalas e de colunas na destilação fracionada do Produto Líquido Orgânico não altera o rendimento e principalmente a qualidade das frações de hidrocarbonetos produzidas, entretanto novos testes devem ser realizados para validar ainda mais esta pesquisa. Vale ressaltar que valores de análises físico-químicas como: ponto de fulgor, índice de saponificação e viscosidade cinemática também apresentaram valores equiparados.

\section{CONCLUSÃO}

Com base no desenvolvimento desse trabalho e considerando os resultados obtidos, é possível concluir que a destilação fracionada pode ser considerada uma excelente rota tecnológica para produção de biocombustíveis que apresentam características semelhantes aos derivados do petróleo. Também chegou-se à conclusão de que a variação de escalas e de colunas não acaba influenciando na destilação fracionada do Produto Líquido Orgânico, isto se deve graças aos valores aproximados obtidos tanto na destilação fracionada em escala piloto quanto na destilação fracionada em escala de bancada, lembrando que em cada processo foi usado uma coluna de destilação distinta.

Portanto, esta pesquisa será melhor estudada e trabalhada pelos autores e colaboradores do Laboratório de Biocombustíveis e Processos de Separações Térmicas da Faculdade de Engenharia Química da Universidade Federal do Pará, visando sobretudo a utilização de novas matérias-primas, novos catalisadores e visando a variação de porcentagem dos mesmos em relação a massa da matériaprima.

\section{REFERÊNCIAS}

Agência Nacional do Petróleo, Gás Natural e Biocombustíveis, Resolução ANP $\mathrm{N}^{\circ}$ 57, DE 20.10.2011 - DOU 21.10.2011.

BARROS, A.A.C., WUST, E., MEIER, H.F. Estudo da viabilidade de técnico-científica da produção de biodiesel a partir de resíduos gordurosos, Engenharia ambiental 2008; 13: 255 -262.

DEMIRBAS, A. "Introduction to Biofuels". Biodiesel A Realistic Fuel Alternative for Diesel Engines, chapter 2, p. 39. Turkey, 2007. 
GEANKOPLIS, C. J. Processos de Transporte y Operaciones Unitárias. $3^{\mathrm{a}}$ ed. México. Compañia Editorial Continental, S.A.C.V., 2008.

MOTA, S. A. P.; LHAMAS, D. E. L., COSTA, E. C., MACHADO, N. T., ARAÚJO, M. E., COSTA, J. M. M., BRANCO, E R. N. C. Investigação da Aplicabilidade de Metodologias Voltadas para a Obtenção de Biodiesel de Óleos Vegetais Na Amazônia. XVIII Congresso Brasileiro de Engenharia Química (COBEQ), 2010.

MOTA, S. A. P. Craqueamento Termocatalítico de Óleos Vegetais em Diferentes Escalas de Produção. 2013. 332.f. Tese (Doutorado em Engenharia de Recursos Naturais da Amazônia) Universidade Federal do Pará. Belém/PA, 2013.

PERRY, R. H. PERRY`S Chemical Engineer’s Handbook, 6th edition, 2008.

SANTOS, A. L. F. Produção de bio-óleo a partir do craqueamento térmico de gorduras residuais derivadas de biomassa animal e vegetal, 2007. Dissertação (Mestrado em Química) - Instituto de Química. Universidade de Brasília. Brasília. 2007.

SANTOS, C.D.; BOFIM, L.M.; MOTTA, J.A.S.; RODRIGUES, G.; NASCIMENTO, A.R.; ARAUJO, A.S. PEDROSA, A.M.G.; SOUZA, M.J.B., 2009. Estudo da pirólise de óleo de soja sobre peneiras moleculares micro e mesoporosas. Scientia Plena, Vol 5, n. 11, 2009.

SANTOS, W.G. Análise e Interpretação de Dados no Processo de Craqueamento Termocatalítico do óleo de Buriti (Mauritia Flexuosa 1.). 2011. 62 f. Trabalho de Conclusão de Curso em Engenharia Química - Universidade Federal do Pará. Belém/PA, 2011.

TREYBAL, R. E. Mass Transfer Operations. Tokyo: Ed. McGraw-Hill 2º edição, 1968. 717p.

WANG, G.; YANG, G.; XU, C.; GAO, J. A novel conceptional process for residue catalytic cracking and gasoline reformation dual-reactions mutual control. Applied Catalysis A: General, p. 98-105, 2008. 